\title{
Investigación \\ El turismo cultural en España como fuente de empleo para los profesionales del patrimonio
}

Jordi Juan Tresserras ' > Juan Carlos Matamala "

\section{Resumen}

El turismo cultural ofrece en nuestro pais una amplia gama de posibilidades de empleo para profesionales relacionados con el patrimonio cultural. En este artículo se analiza la situación actual de este segmento turístico en España, incluyendo el perfil de los turistas culturales tanto nacionales como extranjeros. Los estudios realizados muestran la importancia cada vez mayor que las administraciones están otorgando a este sector turístico. El sector privado ha demostrado un amplio crecimiento en hostelería, pero en cambio es necesario desarrollar y replantear otros servicios y productos turístico-culturales. Por otra parte, se plantea el problema de la accesibilidad a los recursos y productos turístico-culturales, así como el papel cada vez más importante que las TIC están adquiriendo. Finalmente, se han determinado aquellos sectores de la actividad turística, y otros relacionados con el turismo, potencialmente capaces de generar puestos de trabajo para los profesionales del patrimonio, y que ofrecen, a priori, posibilidades para un mercado en crecimiento.

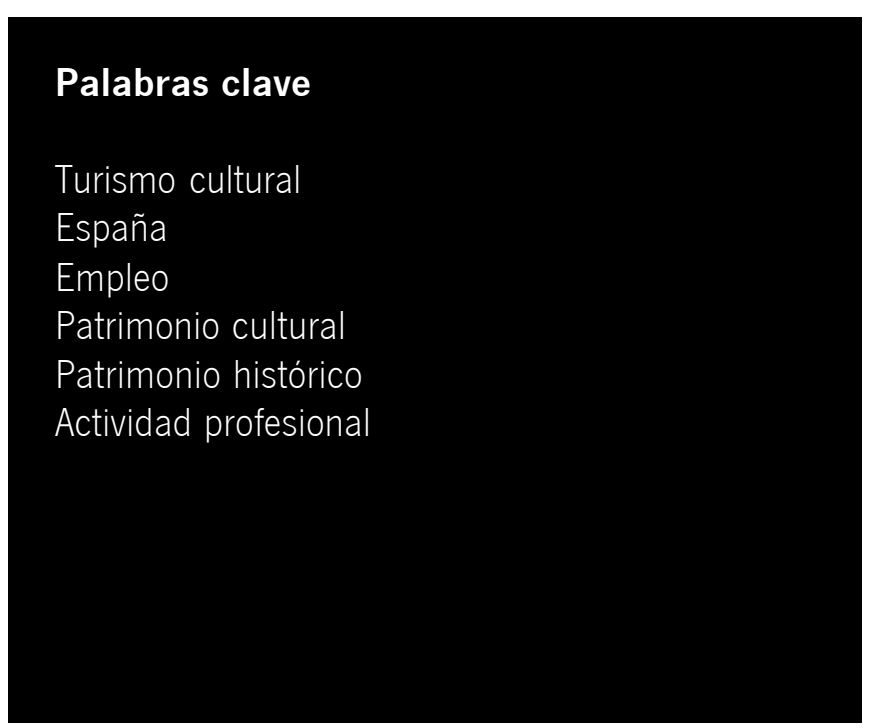

\section{Introducción}

Los profesionales del patrimonio ven en el turismo cultural un yacimiento de empleo en crecimiento asociado a los servicios de ocio. Una de las primeras referencias a la valorización del patrimonio cultural como nuevo yacimiento de empleo aparece ya en el Libro Blanco de Delors (1993) "Crecimiento, competitividad y empleo. Retos y pistas para entrar en el siglo XXI". De todas formas es necesario realizar una profunda reflexión desde nuestra profesión ya que para que el patrimonio pueda tener un uso turístico es necesario planificar no sólo este uso sino garantizar previamente la conservación, el estudio y la valorización del mismo, permitiendo su proyección futura y garantizando su disfrute para la población local. No todo el patrimonio puede ser susceptible de ser transformado en producto turístico y muchos de los productos turísticos que incorporan recursos patrimoniales no contemplan un plan de gestión de los mismos que asegure la conservación y menos aún cómo revertir los ingresos producto del desarrollo turístico en el propio patrimonio.

\section{El turismo cultural en España}

Turespaña realizó en el año 2001 un estudio sobre el turismo cultural en el cual se analizaba la oferta actual y la respuesta de la demanda. El estudio se realizó mediante encuestas a turoperadores, agencias y turistas, tanto extranjeros como nacionales. Como productos estrella destacaron las ciudades de Barcelona (con la diferenciación centrada en la oferta Gaudi-modernismo), Madrid y Andalucia (como destino conjunto). Siguen las ciudades de Granada, Sevilla así como el Camino de Santiago. En tercer lugar, el Museo Guggenheim de Bilbao y las ciudades de Córdoba, San Sebastián, Toledo y los circuitos turísticos que ofrecen visitas a diferentes ciudades con programas de visitas culturales y/o museos, especialmente las Ciudades Patrimonio de la Humanidad.

Sólo el 34\% de los europeos consideraba la marca España como un destino asociado a una buena oferta cultural, muy por debajo de Grecia, Francia o Italia. En el caso concreto de la valoración de la oferta culinaria (tanto como complemento o integrante de la cultura), la española está considerada muy por debajo de sus posibilidades, con sólo un $27 \%$ de valoración frente al $73 \%$ de la cocina francesa.

La comercialización de los productos de turismo cultural se realizaba básicamente en paquetes turísticos con formato de circuito o touring, que se concentraban en el triángulo de las ciudades monumentales de Sevilla, Córdoba y Granada, y que de forma excepcional se ampliaba a otros núcleos como Priego, Úbeda y Baeza, así como a rutas temáticas. Este último caso estaba diri- 


\section{Investigación}

El turismo cultural en España como fuente de empleo para los profesionales del patrimonio

\section{J ordi J uan Tresserras} J uan Carlos Matamala gido especialmente al turismo de fines de semana, excursiones de menos de un día o vacaciones cortas formadas por productos de coste asumible tanto por el precio como por la proximidad, de forma que se constituía como un producto de acceso individual, de pareja, familias o pequeños grupos, en donde la oferta secundaria se valoraba de una forma especial.

Con respecto a la organización del viaje por parte del turista predominaba la organización por cuenta propia, que en el caso de los españoles era del $91 \%$ y del $65 \%$ entre los extranjeros. Las visitas estaban programadas con anterioridad en un $93 \%$ de los casos. Está creciendo el viaje organizado o parcialmente organizado, con fórmulas como el fly and drive, que combinan el transporte aéreo con el alquiler de coches en el lugar de destino. La posibilidad de reservar alojamientos se ha visto potenciada con la presentación de bonos que dan derecho a los servicios anteriormente mencionados.

Según los datos de Turespaña para el 2001, que son los únicos con los que se cuenta a nivel estatal, España recibe anualmente a unos 8.5 millones de viajeros culturales, que representaba un $11 \%$ del total de visitantes. De estos, unos 5 millones son extranjeros, la gran mayoría europeos (un 70\%). Del estudio se deducía que el turista cultural tipo es menor de 50 años, con un cierto dominio de los estudiantes universitarios. Además, destacaban los que venían en pareja y, en menor medida, con la familia, por lo general con un poder adquisitivo medio o alto. En este sentido el gasto medio del turista cultural lo calcularon en 78,3 euros diarios, casi el doble que el gasto del resto de los visitantes. En términos económicos, se calculó que generaban unos 5 millones de euros, y de esta cantidad, unos 4 millones procedian de los turistas extranjeros. Estos 5 millones de euros representan un $12,1 \%$ del total del ingreso turístico en el estado español. Se constataba que una tercera parte de los turistas europeos tenían una motivación cultural. Según el estudio, aproximadamente el $10 \%$ de dicho turismo potencial elegía a España frente a otros países. Así, los europeos se posicionaron como los principales clientes. A pesar de ello, el estudio hace énfasis que España no se considera como un destino preferente de turismo cultural, aunque si se analizan las cifras el país estaría posicionado como el cuarto destino mundial de turismo cultural. En el imaginario europeo continúa situado como destino de sol y playa, pero ganando posiciones en relación con la cultura ya que se ha integrado en la oferta desde los últimos años, especialmente en los destinos de turismo de interior. Aparte de los europeos, se puede decir que el $80 \%$ de los turistas estadounidenses (del millón que visita el país anualmente) lo hace por motivos relacionados con la cultura. En el caso de los visitantes latinoamericanos (unos 700.000) el porcentaje sube hasta el 90\%. Finalmente, el mercado japonés, aunque no es muy numeroso (unos 300.000 visitantes anuales), es un turismo casi exclusivamente cultural. De hecho el 93\% de los japoneses que visitan el
'Profesor asociado del Departamento de Prehistoria, Historia Antigua y Arqueología y
coordinador del Programa de Postgrado en Gestión Cultural. Universitat de Barcelona
" Coordinador de Proyectos del Programa de Turismo Cultural. Universitat de Barcelona

país manifiestan que lo hacen para conocer otras culturas. En cuanto a los turistas españoles, según las encuestas, viajan por motivaciones culturales un 30\% dentro del territorio nacional, y un $8 \%$ en el extranjero. La aportación nacional al turismo cultural está cuantificada, según diversas fuentes, en unos 12 millones de viajes.

La duración media de un viaje cultural es de unos 8,3 dias, dentro del conjunto de todos aquellos turistas que dicen que vienen a España atraídos por motivos culturales. Hay que destacar el caso de los latinoamericanos, que prolongan su estancia hasta 15 días, seguidos por los japoneses, que están 13 dias. Los norteamericanos pasan unos 11,3 dias, los británicos 8,3 días, los alemanes 7,8 días y los franceses 5,6 dias. En última posición encontramos a los turistas españoles con una media de 4,4 dias. De todas formas, otras encuestas turisticas indican que la duración más representativa es de una semana (30\% de los visitantes), un porcentaje muy similar a lo que muestran las estancias de dos semanas y las que se hacen de uno a tres días.

En relación con el tipo de alojamiento, los extranjeros utilizan en su gran mayoría los hoteles de tres estrellas (40,8\%), seguidos de los de cuatro estrellas (28\%), y los apartamentos (14\%). En el caso de la red de Paradores Nacionales, la pernoctación supone un $7,2 \%$ de la demanda extranjera, y un $5 \%$ de la española, dentro de este segmento de turismo cultural.

Los turistas culturales son probablemente los que mejor preparan sus vacaciones y su presupuesto. Según los datos oficiales el gasto por persona y día es de unos 78,3 euros, que es un poco mayor en el caso de los japoneses. Con los mismos datos se calcula que el gasto final de los europeos es de unos 600 euros por persona, siendo mayor el gasto en el caso de los turistas que llegan de otros continentes, por el coste añadido del transporte aéreo. Con respecto al turista español, el gasto es de unos 330 euros por persona. Si se hace una comparativa, el gasto es el mismo en cualquiera de las áreas turísticas escogida y sólo el transporte se conforma como un elemento diferenciador. Los turistas manifiestan en un $76 \%$ que el gasto es normal, bajo en un $15 \%$ o caro en un $8 \%$. Dentro del bloque de gastos considerados bajos, los extranjeros destacan el precio de la comida, las entradas en museos y en otros recintos, asi como el transporte interno y el alojamiento.

La apuesta por el turismo cultural realizada por Turespaña se basó en diversas medidas para impulsar este segmento-mercado: el Estudio de Turismo Cultural (2001) al que se hacía mención anteriormente y el Estudio del Turismo Idiomático (2001), que sirvieron para establecer el Plan de Impulso al Turismo Cultural e Idiomático (2002) que tuvo como principales acciones el nombramiento del 2002 como año del Turismo Cultural con la capitalidad europea de la Cultura Salamanca 2002, en la que se 
organizó el I Congreso Internacional de Turismo Cultural y la apuesta por celebraciones y eventos como el Año Gaudí 2002, Xacobeo 2004, el Forum Internacional de las Culturas Barcelona 2004, el Año Dalí 2004... o apuestas como la capital europea de la cultura 2016 que se disputan Cáceres, Córdoba, Málaga y Tarragona. Todas estas iniciativas buscaban crear una oferta competitiva que permitiera un reposicionamiento en un mercado turistico voluble y dinámico, en donde cada vez con más rapidez, las tendencias cambian y surgen nuevos retos y competidores (aparición de nuevas tecnologías, irrupción de las aerolíneas de bajo coste o los cambios en el perfil del turista).

Dentro de este panorama, el turismo cultural está creciendo y consolidándose como producto-mercado. Cada vez son más las ciudades que se perfilan como destinos urbanos y culturales, algunas como Bilbao y Valencia que han apostado por ese posicionamiento. El componente cultural centra la promoción del turismo de interior y supone un valor añadido cada vez más destacado en la oferta de turismo rural.

En relación con el turismo cultural destaca el portal de turismo de España, www.spain.info. Esta herramienta ofrece en estos momentos una de las mayores bases de datos y recursos audiovisuales interactivos existentes en la red. Está orientado al mercado internacional, con un entorno que permite la consulta en siete idiomas, una amplia gama de información sobre destinos turísticos y servicios de ayuda de planificación. En su lanzamiento en el año 2003, el producto "España cultural" fue el primero en promocionarse con el fin de desestacionalizar la oferta y el marco de la campaña de promoción del turismo cultural que había llevado a organizar el I Congreso Internacional del Turismo Cultural en Salamanca (noviembre 2002). Le siguieron los productos de "Sol y Playa", "Deportes y Naturaleza'" y "Turismo de Negocios". Los objetivos planteados pretendían consolidar el liderazgo español en el turismo vacacional a nivel mundial; posicionar a España como destino turístico cultural de primer orden, incrementando su cuota de participación; diversificar la oferta turística española; potenciar la imagen de la marca "España" y liderar la promoción turistica, mediante una utilización creciente de las tecnologias de la información y comunicación (TIC). La campaña basó su estrategia en la combinación de alianzas con los principales portales generalistas y de viajes; publicidad on

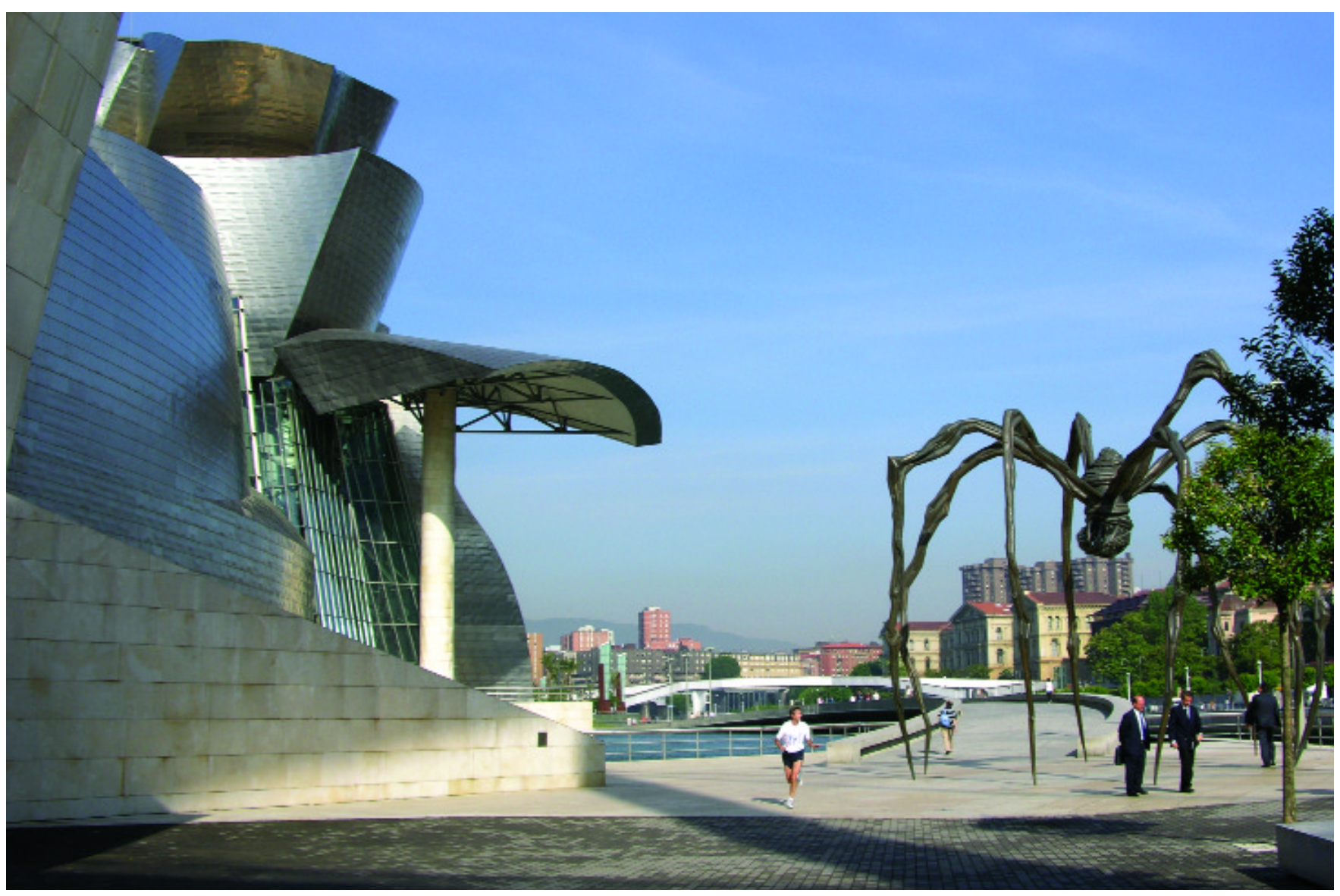




\section{Investigación}

El turismo cultural en España como fuente de empleo para los profesionales del patrimonio

\section{J ordi J uan Tresserras} J uan Carlos Matamala line; e-mail márketing y posicionamiento en buscadores. Con esta campaña, gestionada por la Sociedad Estatal de Gestión de la Información Turística (SEGITUR), que duró de julio de 2003 a enero de 2004, se consiguieron más de 325 millones de impactos en la web, frente al objetivo previsto de 200 millones. Se generó cerca de dos millones de visitas directas y se movilizaron 66 millones de usuarios por la campaña, frente a los 20 millones previstos. Participaron más de 200 portales de 19 países y 400.000 usuarios recibieron información vía e-mail; se crearon 28 canales temáticos sobre España en los portales de la campaña y se dieron de alta 6.250 palabras en más de 50 buscadores. La campaña ya ha recibido dos galardones: premio al mejor anuncio del año en Internet, concedido por la revista Anuncios, y premio a la mejor acción de publicidad on-line, otorgado por la revista Interactiva.

La segunda campaña del portal de Turespaña lanzó a finales de 2004 y cuenta con una presencia en 19 paises y una financiación de 3,2 millones de euros. Cultura y ciudad se promocionaban como productos junto al turismo idiomático, sol y playa y golf. Respecto a las acciones que componen esta campaña, destacan en primer lugar las alianzas que se han establecido con los principales portales generales (Yahoo, Terra, Wanadoo, etc.) y portales de viajes (Lastminute, Expedia, Tiscali, etc.). La segunda acción destacada es la publicidad online, que se realizó en medios afines y de relevancia en cada país, así como en algunos soportes digitales de los medios en los que estuvo presente la campaña offline. El e-mail márketing también estuvo presente en esta campaña online, y para ello se adquirieron bases de datos de usuarios de internet que han mostrado interés por el sector de viajes. Cerca de 250.000 personas recibieron un correo electrónico informándoles de la existencia de www.spain.info. Del mismo modo la optimización en buscado-

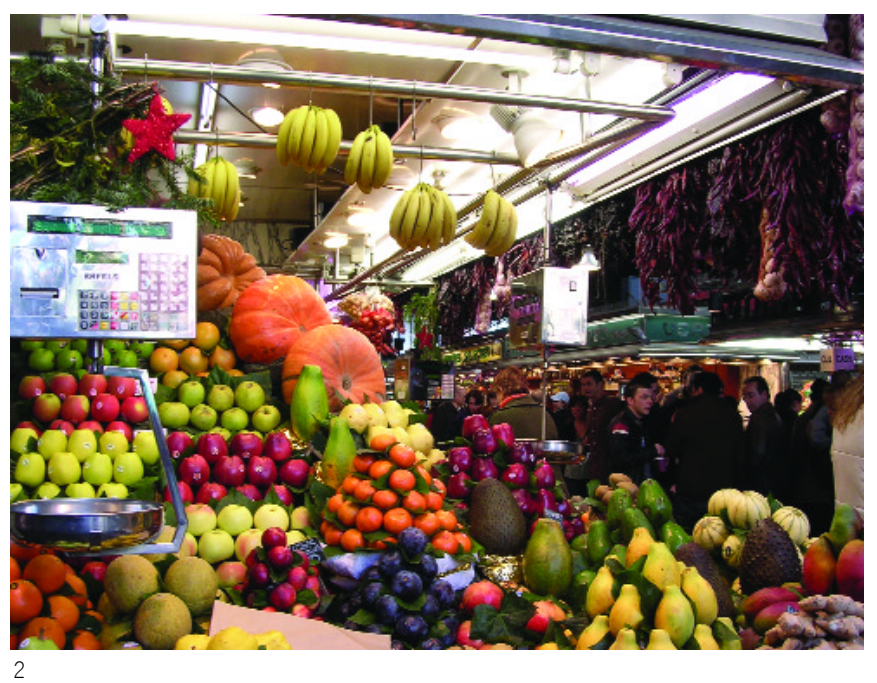

2. Mercado de la Boquería (Barcelona)

3. Punto de información turística. Plaza de España (Barcelona) res fue otra de las acciones previstas. Por último, la campaña incluyó links patrocinados, acción a la que se ha dedicado cerca del $10 \%$ del presupuesto.

Desde el portal de Turespaña es posible acceder a las webs turísticas oficiales de las diecisiete comunidades autónomas. Olavide et al. (2004) realizaron, a finales de 2003, un estudio sobre las mismas cuyos resultados se presentaron en Turitec 2004. Andalucia y Euskadi disponen de las webs que más información ofrecen, mientras que Castilla-La Mancha, la Comunidad de Madrid y Canarias son las que presentan menos contenidos globales. La práctica totalidad de las webs de las comunidades ofrecen información sobre la situación geográfica del destino, los principales municipios de la zona, las fiestas populares, la gastronomía típica y los museos. Sin embargo, ninguna recomienda cuál es el vestuario necesario para visitar una determinada zona y sólo una informa de cuáles son las salidas recomendadas a puntos turísticos vecinos de interés. En general, los autores de la investigación manifiestan que se desprende un bajo nivel general de aprovechamiento de las posibilidades comerciales de esta tecnología. De hecho, las webs de las comunidades autónomas españolas apenas permiten la posibilidad de realizar reservas y, aún menos, de realizar compras y pagos directos. Únicamente Andalucia, Baleares y Galicia contaban con estos dos recursos, aunque con diferentes grado de desarrollo. Andalucia ofrece hipervínculos a páginas externas que funcionan como centrales de reserva. Galicia integra en sus páginas un espacio para realizar reservas y pagos relativos a diez establecimientos de alojamiento. Andalucía, Aragón, Galicia, Baleares, Murcia y la Comunidad Valenciana ofrecian a través de su web un apartado en el que incluyen ofertas. En este sentido, Díaz et al. (2004) remarcan el escaso esfuerzo realizado por parte de las oficinas de marketing de los destinos para ejercer de intermediarios turísticos. Respecto a los idiomas de presentación de las webs, únicamente Extremadura y Galicia emplean cinco lenguas extranjeras. Las webs de Aragón, Cantabria, Castilla La Mancha, Castilla León y La Rioja sólo tienen sus contenidos en castellano. Los idiomas más utilizados son el inglés (12 ocasiones), el alemán (11) y el francés (10). En un segundo plano se sitúa el italiano (3) y el portugués (2). En algunas comunidades se ofrecen también contenidos en otras lenguas oficiales del Estado, aparte del castellano. El catalán se documenta en 4 ocasiones, el eusquera en 2 y el gallego únicamente en la web de Galicia.

En el mismo congreso Turitec 2004, Antón y Villalta (2004) analizaron los sitios web de los destinos turísticos mediterráneos del litoral español. En relación con el turismo cultural destacan la Costa del Sol, la Costa Daurada y Baleares. Los dos primeros, junto con la Costa Blanca, son los únicos que presentan algún tipo de visita o excursión virtual. La Costa Daurada plantea el turismo cultural como una de las únicas ofertas alternativas/ complementarias al sol y playa. La Costa del Sol es el único destino que plan- 
tea una estrategia clara de comunicación de múltiples líneas de producto, con 11 modalidades, entre las que destaca como se hacía mención con anterioridad el turismo cultural. No en vano la inauguración del Museo Picasso en Málaga con una importante promoción turística y la realización de una feria especializada en turismo cultural en la ciudad testimonian este posicionamiento.

Según los datos del Ministerio de Industria, Comercio y Turismo, mientras uno de cada diez españoles utiliza la red para buscar información y organizar sus vacaciones, en el caso de los extranjeros que visitan España, este porcentaje se aproxima al 40\%. No en vano España desde hace tiempo está impulsando la utilización de las nuevas tecnologías en relación con una mejora de la promoción y la comercialización del turismo.

De todos modos el uso de Internet se emplea básicamente para consultar información, siendo aún limitado la reserva de servicios y pago de los mismos entre los turistas extranjeros que eligen España como destino turístico, y todavía más reducido entre los viajeros nacionales. Sin embargo, las cifras aumentan cada año, especialmente en las franjas de edad más jóvenes.

Algunos denominan a esta nueva figura "turista interactivo", caracterizado porque realiza sus reservas on-line de transporte y alojamiento, contrata algunos servicios (alquiler de vehículos, reserva anticipada de entradas a monumentos y/o espectáculos...) y que, por lo general documenta su viaje previamente por internet a través de páginas web.

Para el 2005, Turespaña ha desarrollado una nueva campaña internacional de publicidad bajo el lema "Smile, you are in Spain". Respecto a la distribución de la publicidad por mercados, Europa concentra el $82,6 \%$ y los mercados del Reino Unido y Alemania concentran las partidas más importantes. En América se va a destinar el 11,8\%, con una atención especial a Estados Unidos, mientras que Asia dispondrá del 5,6\%. Por primera vez, se incluye publicidad en China para ir creando una imagen de destino. En relación con la distribución por productos, se ha priorizado el producto vacacional tradicional de sol y playa con el 50\% del presupuesto. El 35\% irá hacia el turismo cultural y de ciudad; el $10 \%$ al deportivo y de naturaleza y el $5 \%$ restante al turismo de reuniones y congresos.

La mayor parte de los destinos están desarrollando estrategias de tematización o de la multitematización de su territorio para la presentación de productos de turismo cultural orientados tanto al turismo de proximidad como al turismo internacional. El patrimonio cultural suele ser la base sobre la que se estructura la mayor parte de propuestas (Juan Tresserras, 2001). Este tipo de realizaciones generalmente reúne diferentes equipamientos o instalaciones bajo un mismo hilo conductor, que permite tanto el conocimiento de la evolución histórica de la ciudad (como es el caso de

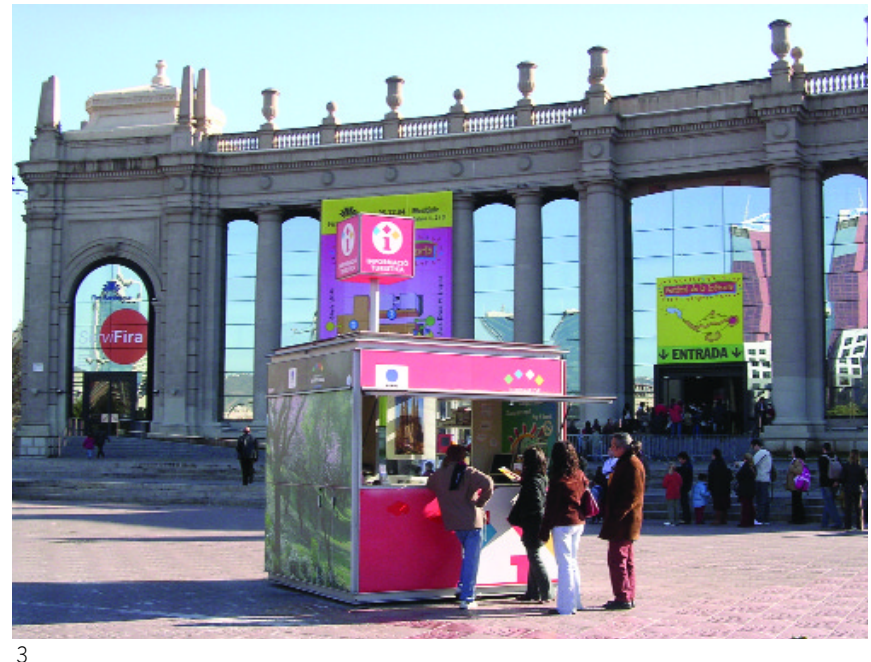

Lorca, Taller del Tiempo), como un periodo cronológico que permite destacar algún aspecto diferencial o singular (las actuaciones en la Zaragoza y la Tarragona romanas son un claro exponente; la ciudad de Girona realizó una labor de posicionamiento ante otras ciudades medias con pasado medieval que fue la recuperación y dinamización del barrio del Call de Girona, desde donde se coordina la secretaría de la Red de Juderías de España; así como el modernismo en ciudades como Barcelona, Reus, Sitges y Terrassa), o un determinado personaje de renombre internacional (sirva de ejemplo Gaudi y Picasso en Barcelona, Dalí en Figueres o recientemente Picasso en Málaga).

Otro claro ejemplo de cooperación es la creación de redes que permitan crear y consolidar sinergias entre destinos y espacios: Art Cities in Europe, la Organización de Ciudades Patrimonio de la Humanidad, la Red de Juderías de España, el Camino de Santiago... La mayor parte de estas iniciativas están centradas en la promoción y comercialización conjunta, orientada a diversificar la oferta mediante la creación de productos que distribuyan mejor los flujos turísticos entre los distintos recursos y a lo largo del año, obteniendo así una mejor rentabilidad de las infraestructuras existentes. Como señala Marchena (1998) es necesario orientar la promoción hacia la educación cultural de la demanda. Una adecuada gestión en este sentido puede conseguir satisfacer al turista e incentivarlo a que repita su visita en el mismo destino o a que pruebe otro destino dentro de la propia red (fidelización).

\section{El principal obstáculo: la accesibilidad al patrimonio cultural y su integración en la oferta turística}

Podriamos mencionar que los principales problemas del turismo 


\section{Investigación}

El turismo cultural en España como fuente de empleo para los profesionales del patrimonio

\section{J ordi J uan Tresserras} J uan Carlos Matamala

cultural en España son, entre otros: la poca existencia de catálogos en los que acceder a listados de productos culturales y de turismo cultural (aunque se está haciendo un esfuerzo en este sentido), las deficientes condiciones de accesibilidad en la mayor parte de recursos, la necesidad de reconsiderar las politicas de promoción que las entidades públicas y empresas privadas tienen que desarrollar para que el producto sea una auténtica oferta turística, el problema grave que supone la baja comercialización de los productos de turismo cultural dentro de las ofertas existentes de las agencias de viajes y turoperadores extranjeros; por otra la carencia de operadores turísticos especializados y la presentación de productos que ya existen en el mercado dentro de una oferta muy concentrada en los principales destinos turísticos y en temáticas ligadas en las marcas más conocidas; asi como la tendencia a proponer rutas y/o itinerarios que muestran graves carencias de gestión. En este sentido tenemos que remarcar que una ruta no se puede mostrar como un simple título o marca de producto turístico.

La principal necesidad de cualquier tipo de turista es acceder a la propia información tanto antes de iniciar el viaje como durante su estancia en el lugar de destino; en ambos casos está cobrando cada vez más relevancia el uso de las tecnologías de información. Y, evidentemente, los puntos básicos que demanda este tipo de turistas son: cómo llegar, dónde comer, dónde dormir y las actividades culturales que ofrece la zona.

Un producto cultural de tipo patrimonial es un recurso patrimonial en el que se puede realizar una actividad determinada, principalmente la visita pública, ya que se ha formulado una propuesta de accesibilidad al mismo. El paso de recurso patrimonial a producto cultural se realiza en tres fases: identificación, conceptualización, creación y gestión del producto cultural. El mayor problema al que nos enfrentamos es que en muchas ocasiones no se han seguido estas tres fases para poner en marcha el producto cultural. Es decir, un recurso cultural se ofrece como producto turístico sin estar preparado para ello provocando a menudo problemas de accesibilidad, falta de señalización, falta de oferta complementaria... Otro aspecto fundamental es que una vez se ha creado el producto es necesario mantener un programa de acciones de comunicación, generales o específicas, dirigidas a los diferentes sectores de público para consolidar el producto cultural en la oferta cultural de la localidad.

Garantizar la accesibilidad es la clave para la creación de productos culturales susceptibles de integrarse en una oferta de turismo cultural. En este sentido es importante diferenciar entre la accesibilidad cultural, temporal, espacial y económica.

\section{$>$ Accesibilidad cultural}

La accesibilidad cultural implica poder otorgar unas normas básicas que le permitan al visitante poder interpretar el recurso cultural con su formación y aprendizaje previo. Los responsables de la puesta en valor del recurso deben hacer llegar un mensaje educativo adaptado al perfil de los visitantes y presentar una señalética acorde a los mismos y a su forma de acceso y de uso. En este sentido, es importante reflexionar sobre quién es nuestro interlocutor y tener en cuenta que lo que es obvio para nosotros no tiene por qué serlo para él. Diferencias de religión, valores, códigos éticos... pueden interferir con facilidad por lo que es necesario comunicar para evitar conflictos. La información ofrecida no debe quedarse únicamente en la explicación genérica y de acceso al recurso sino que también debe advertir desde el respeto a la intimidad para visitar patios y casas particulares, a indicaciones para fotografiar determinadas manifestaciones culturales o sobre el uso de vestimenta adecuada para visitar edificios y conjuntos religiosos o incluso explicar en qué consisten un determinado plato o producto gastronómico. Otras veces el propio producto turístico-cultural precisa de una mayor dosis de esfuerzo para contextualizar y situar a los visitantes, como sucede especialmente con productos asociados a períodos o sucesos históricos (caso del Camino de los Buenos Hombres - Ruta de los Cátaros en Catalunya, o el caso de la Ruta del Temple "Domus Templi", o la Ruta Vía de la Plata).

\section{$>$ Accesibilidad temporal}

Uno de los grandes problemas de la accesibilidad a los recursos culturales suele ser el temporal por lo que es preciso adaptar el acceso a las necesidades horarias, temporales y climáticas. El desarrollo del turismo cultural ha propiciado que los equipamientos abran los lunes, tradicionalmente festivos para museos y monumentos, que se realicen acciones para visitar los equipamientos en obras, como ha sido el caso exitoso de la Catedral de Vitoria o de las intervenciones arqueológicas en el antiguo Mercat del Born de Barcelona. Las peripecias para acceder a las llaves de ermitas e iglesias perdidas por la geografía española se han podido eliminar en algunos casos gracias a los programas de visitas concertadas o a la privatización de las visitas mediante conciertos con empresas y/o licitación de servicios, como es el caso de las iglesias de l'Alt Berguedà en la provincia de Barcelona que permiten por el concierto con Dinamització del Patrimoni S.L. la visita guiada en horario continuo durante los fines de semana y la visita guiada concertada los dias laborables. Estos guías de sitio hacen a su vez las funciones de informadores turísticos informando sobre otras ofertas culturales y, especialmente, los equipamientos turísticos existente en la zona, básicamente restaurantes de cocina tradicional y de productos de temporada que suelen ir asociados a las visitas de los fines de semana.

Otros casos implican la modificación de los horarios en función 
4. Iglesia de San Miguel de Lillo (Oviedo, Asturias). Imagen: Myriam Olmedo

5. Chillida Leku (Hernani, Guipúzcoa). Imagen: Dolores Lobillo

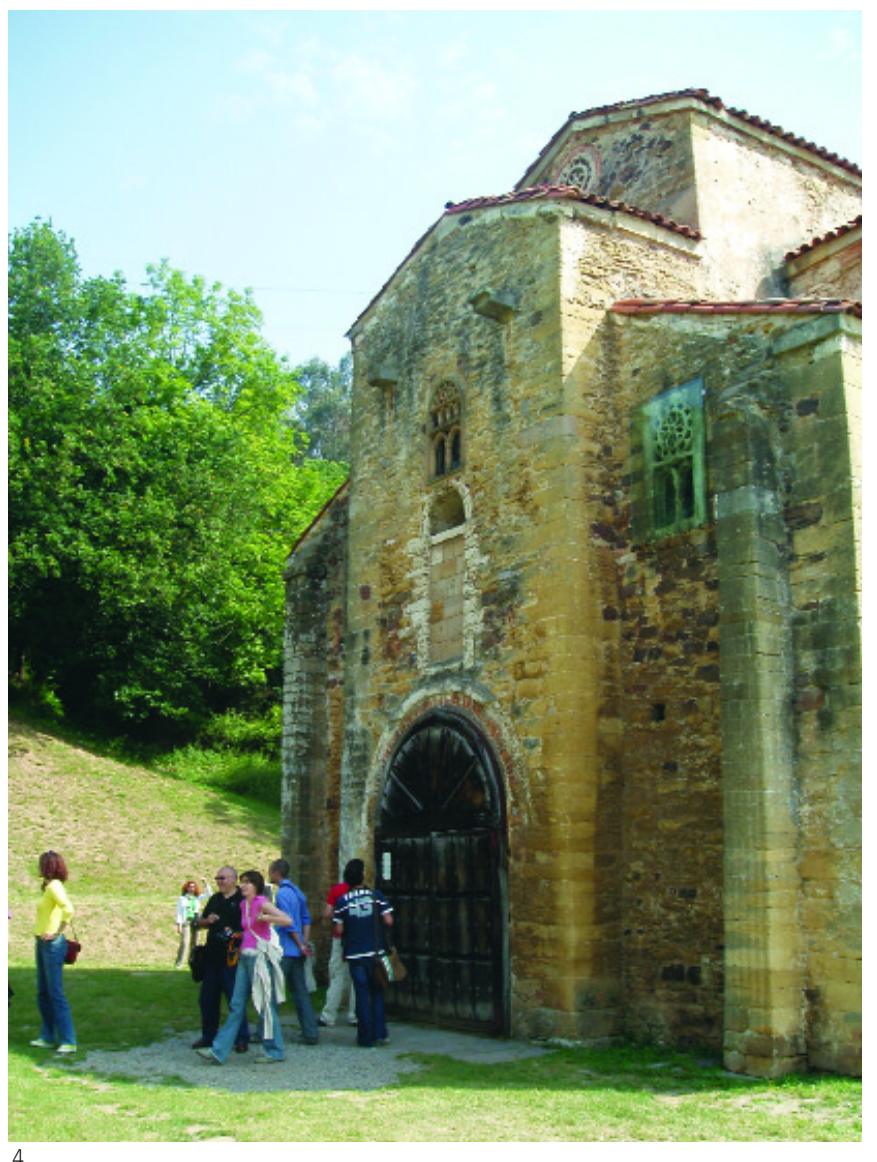

de las peculiaridades climáticas, como en el caso de determinados yacimientos arqueológicos (Ciudadela Ibérica de Calafell), en los que los meses de verano se ha habilitado un horario de visita nocturna, ya que el calor imperante en las horas centrales del día hace poco atractiva la visita.

De esta forma, se pretende que los horarios de los equipamientos sean compatibles con la actividad turística; de todas formas aún es frecuente en nuestro pais que determinados recursos $u$ ofertas turístico-culturales se encuentren cerrados (p.e. por vacaciones del personal) en las fechas de máxima afluencia turística. Por ello, se hace necesaria una mejor coordinación entre los agentes turísticos y los agentes culturales en las áreas en las que se ubican estos recursos o productos.

\section{$>$ Accesibilidad espacial}

Esta modalidad de accesibilidad es fundamental ya que se sustenta en una buena señalética indicativa para llegar al recurso, pero también in situ, tanto para que los visitantes puedan moverse adecuadamente, como para poder interpretar dicho recurso.

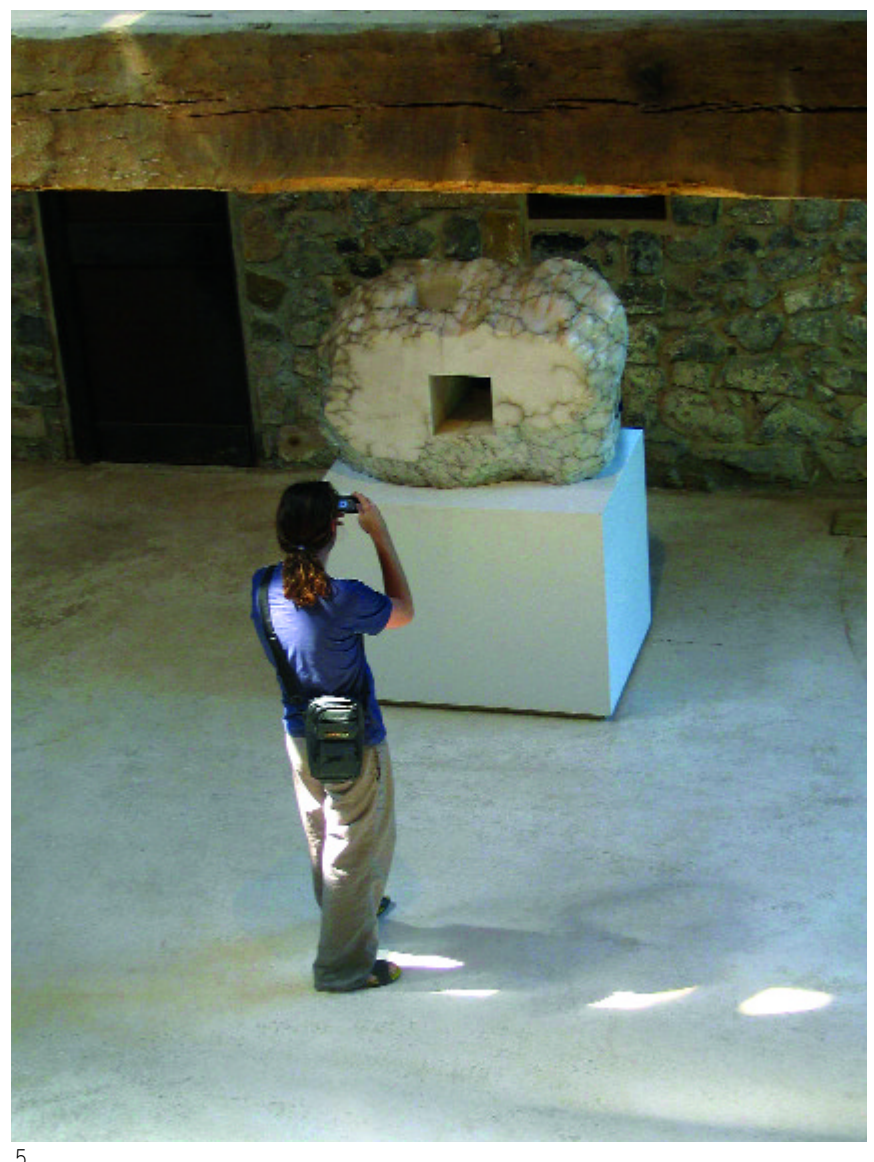

Obviamente, esta accesibilidad implica una adecuación y adaptación a personas de movilidad reducida (sillas de ruedas, gente mayor, familias con niños pequeños...) y a personas que tengan discapacidades (sean visuales, auditivas...). Debe ofrecer también recursos que permitan una adecuada movilidad, como zonas para sentarse, servicios higiénicos...

Sobre los lugares adaptados a personas de movilidad reducida o con otro tipo de discapacidades es importante el acceso a la información y la actualización de la información.

\section{$>$ Accesibilidad económica}

La valorización del patrimonio supone garantizar también la accesibilidad a todos los públicos, por lo que es importante desarrollar estrategias con una política definida de precios de servicios y productos adecuadas tanto a la ciudadanía como a los visitantes. La mayoría de las veces la falta de información sobre las denominadas City Cards (especialmente dónde se compran, cuánto cuestan y qué ventajas más ofrece) reduce su venta a los 


\section{Investigación}

El turismo cultural en España como fuente de empleo para los profesionales del patrimonio

\section{J ordi J uan Tresserras} J uan Carlos Matamala

organizadores de congresos y eventos que las adquieren para ofrecerlas en los paquetes a congresistas. También es importante difundir adecuadamente otros productos como pases de temporada (por ejemplo para un festival o ciclo de conciertos), descuentos con carnets (ya sean de estudiante, clubs infantiles u organizaciones profesionales), multientradas, jornadas de puertas abiertas, dias de gratuidad (p.e. primer domingo de mes)...

\section{El turismo cultural y el empleo}

Lamentablemente no se dispone de datos sobre el número de empleos asociados directamente con el turismo cultural en España. Es obvio que genera tanto empleos directos como indirectos ya que buena parte de los equipamientos culturales de los principales destinos turísticos son a su vez atractivos básicos o complementarios de los mismos. De todos modos la mayor parte del empleo asociado al turismo cultural no es el exclusivamente el derivado de los puestos relacionados con museos o monumentos, guías o informadores turísticos. Existe un buen número de empleos indirectos como los relacionados con la recuperación del patrimonio y sus usos turísticos ya sea de forma directa o indirecta, o los relacionados propiamente con el turismo como la hostelería, la restauración o la venta de artesanías que comparten una clientela común cuando el foco de atracción es lo patrimonial. A diferencia de otros subsectores turísticos especializados, como el ecoturismo, falta aún consolidar la profesionalización y una conciencia de pertenecer a un colectivo, en cierta manera por la satanización y los miedos que despierta en el sector cultural, especialmente en la academia, el turismo cultural. El turismo cultural tampoco cuenta por el momento con un corporativismo asociativo que represente al mundo empresarial. Desde finales de los 80 aparece el turismo cultural en los programas formativos, especialmente en los ocupacionales debido a su consideración como nuevo yacimiento de empleo. Las universidades no consolidan programas especializados hasta el año 2000 con el primer postgrado en turismo cultural impartido por la Universitat de Barcelona. En estos momentos la Universitat Politècnica de València, la Universidad de Castilla la Mancha o la Universitat Oberta de Catalunya también ofrecen una oferta formativa especializada. Estos programas están contribuyendo a generar investigación aplicada, desarrollo de proyectos de turismo cultural y a consolidar la profesionalización.

En algunos casos los organismos culturales se han convertido en promotores de nuevos productos turistico-culturales para posicionarlos en el mercado y buscar el interés de los agentes turísticos, como p.e. el Museu d'Arqueologia de Catalunya con la Ruta de los Íberos. En otros casos ha sido la convergencia de intereses para reposicionar un destino como es el caso de Málaga con Picasso y la Feria Internacional del Turismo Cultural. A pesar de ello, una buena parte del sector cultural es aún reacio a conside- rar el turismo dentro de sus políticas, incluso de considerarlo como un elemento para la valorización del patrimonio y el desarrollo de las industrias culturales. Por el contrario, desde el sector turístico no sucede lo mismo ya que se considera un segmento potencial, por lo que es necesario el establecimiento de una negociación fluida para evitar riesgos irreversibles. Para valorizar las posibilidades del turismo cultural deben complementarse los sectores público y privado. El crecimiento de nuevos productos como el turismo idiomático, el turismo gastronómico o los vinculados a acontecimientos y conmemoraciones especiales es una evidencia de este proceso.

Los fondos europeos invertidos a través de programas como LEADER+ o PRODER en las zonas rurales o URBAN en las ciudades están incidiendo positivamente como acicates para el desarrollo de nuevas propuestas turísticas basadas en el patrimonio como eje conductor. En el caso de España, el programa de Escuelas Taller y Casas de Oficios, financiado a través del Fondo Social Europeo, ha desarrollado programas formativos asociados con el turismo cultural que han incidido en el surgimiento de algunas iniciativas empresariales. Programas como INTERREG o Cultura 2000 que fomentan la creación de redes de cooperación también dedican una especial atención al patrimonio y al turismo. Otros, como la iniciativa comunitaria EQUAL, tiene un claro exponente en el proyecto Cultur@civitas ${ }^{1}$, que se plantea fomentar la igualdad de oportunidades entre mujeres y hombres a través de la explotación del patrimonio cultural local, siendo el turismo una de las líneas de intervención.

Es necesario reflexionar sobre la proliferación de equipamientos culturales creados con fondos europeos, especialmente centros de interpretación o de museos de sitio que, en muchas ocasiones, se ponen en marcha por el afán de alguna persona o institución o gracias a la financiación esporádica que no asegura ni su supervivencia, ni su mantenimiento, ni una adecuada dotación de personal. En muchos casos se pretende que sean dinamizadores de la economía local y ejes vertebradores del desarrollo turístico.

Esta fragilidad de las nuevas infraestructuras dependientes de fondos comunitarios va asociada también a la falta de personal especializado en turismo en los equipamientos patrimoniales, ya sea parques arqueológicos, museos, edificios históricos, conjuntos monumentales o centros históricos. Los centros que suelen contar con personal específico para la gestión turística suelen ser los sitios más visitados o aquellos que quieren tratar de serlo y por tanto se posicionan al respecto. Este personal se reduce a la gestión de grupos en destino mediante la regulación del servicio de visitas, la elaboración de material de apoyo en diferentes lenguas (muchas veces sin emplear las estadísticas disponibles para producir de acorde con la demanda existente o prevista), la atención al público y las visitas guiadas en diferentes idiomas. En 


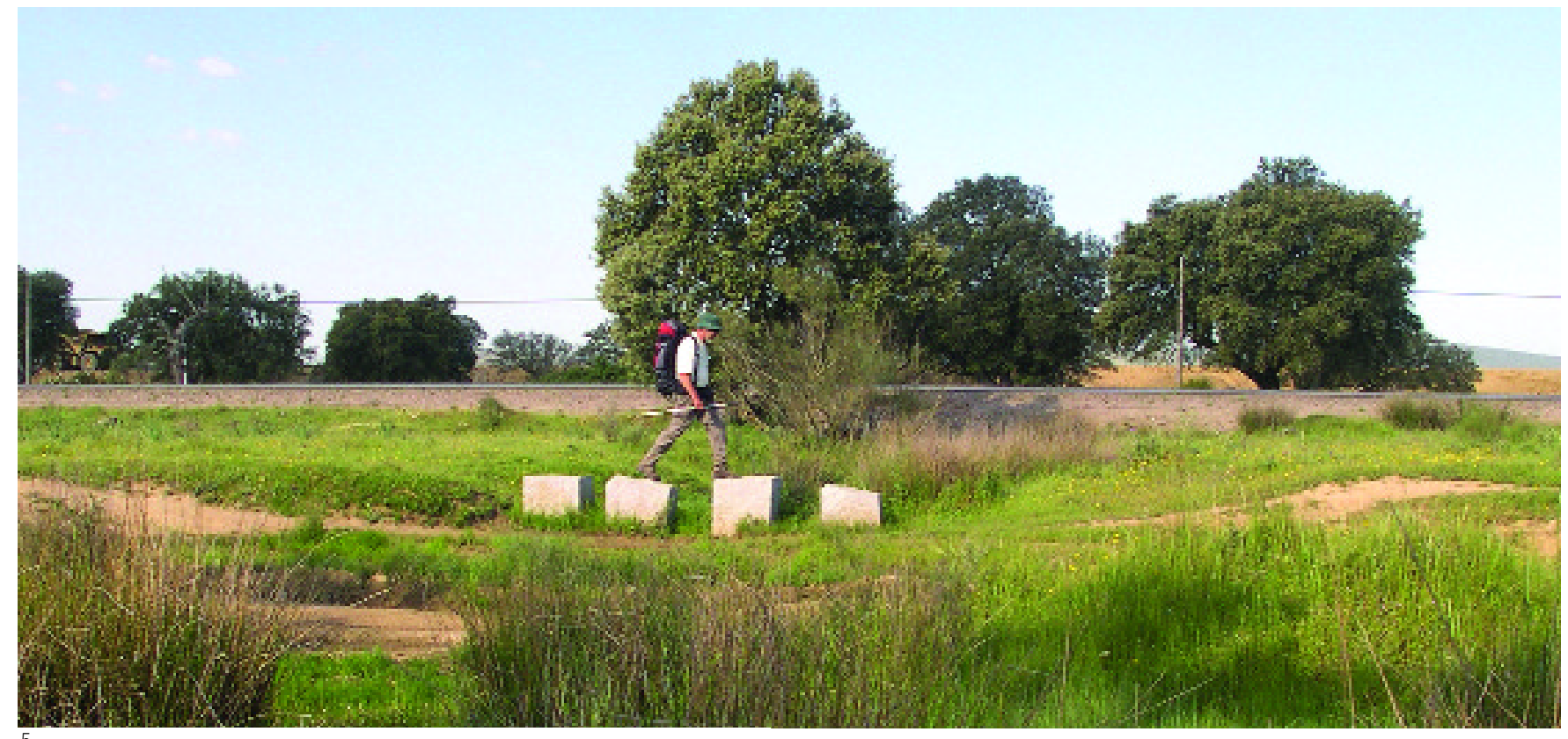

equipamientos de zonas turísticas, por lo general, predomina el empleo temporal y vinculado a la estacionalidad, donde becarios y personal en prácticas suplen una buena parte de las plazas laborales.

En las administraciones públicas y organismos mixtos de promoción turística en España son pocos los entes que tienen personal de plantilla especializado en turismo cultural y cuando lo tienen generalmente comparten el trabajo de este segmento de mercado con otros, como puede ser turismo de ciudad o incluso turismo de congresos. La creación de organismos de coordinación entre los agentes culturales y turísticos, como fue el caso del Club Cultura en Turisme de Catalunya, están condenados al fracaso si no van acompañados de un plan de acciones acordes con la realidad y la financiación necesaria para implementarlas.

El sector privado ha respondido más rápido, en parte por la propia evolución de la demanda. Es difícil todavía realizar un análisis de las empresas y servicios exclusivos del turismo cultural, ya que no existe, al menos de momento, tal categoría sistematizada. Son muchas las empresas de servicios culturales que han realizado una reconversión o una diversificación para poder atender la demanda turística o crear productos y servicios para captarla mediante la organización de programas de visitas (la mayoría con cierta flexibilidad y diseño de rutas a medida), eventos culturales, dramatizaciones... Por lo general son microempresas especializadas en una localidad o en territorio determinado.

Algunos agentes receptores y turoperadores también han optado por el turismo cultural, en algunos casos centrándose en él como elemento de especialización. En relación con la intermediación algunas agencias de viajes, debido a la adaptación del sector a los cambios del mercado han optado también por la especialización o por la creación de receptivos u operadores. De todos modos cabe recordar que en el turismo cultural predomina la organización por cuenta propia y el volumen de los paquetes organizados es escaso.

Se están desarrollando propuestas que se enmarcan en lo que se denomina turismo creativo donde el turista toma realmente un papel activo. En el caso de los programas vinculados con el Año de la Gastronomía que se celebran en Barcelona entre 2005 y 2006 es posible realizar una visita turistica al Mercado de la Boquería y realizar una clase de cocina con los ingredientes adquiridos previamente en el mismo mercado y degustar posteriormente los platos resultantes con una cata de vinos. Esto ha generado que varias empresas hayan incluido estos programas en su oferta.

En este sentido el papel de los guias es fundamental. La incursión de las empresas de servicios culturales y la incorporación de los equipamientos culturales con los guías de museos y monumentos ha conllevado en algunos momentos a una cierta confrontación. Esto ha provocado una mayor profesionalización y estructuración del colectivo. En los productos de turismo cultural el papel del guía suele ser esencial hasta el punto de que algunas empresas citan su nombre y especialidad para dar valor añadido al producto.

Los informadores turísticos se consolidan también como profe- 


\section{Investigación}

El turismo cultural en España como fuente de empleo para los profesionales del patrimonio

\section{J ordi J uan Tresserras} J uan Carlos Matamala

sionales especializados ya que son esenciales para facilitar las condiciones de accesibilidad de los visitantes a los recursos/productos turísticos según el grado de interés en los mismos y las estrategias definidas de turismo cultural según las politicas culturales y turísticas de la localidad. En relación con el tipo de visitantes suele existir una mayor diferencia entre el turismo de proximidad (en teoría mayor conocedor de los recursos culturales) y el turismo extranjero (aunque en determinados casos el nivel de motivación de la visita puede conllevar también un conocimiento previo). Existen informadores turísticos de calle que pueden denominarse también paseantes o simplemente informadores de calle que, generalmente en pareja, recorren las principales calles de las ciudades para atender, en cualquier momento las demandas que requieran los turistas. Son fácilmente identificables por el color llamativo de sus uniformes, amarillo (como en Zaragoza o

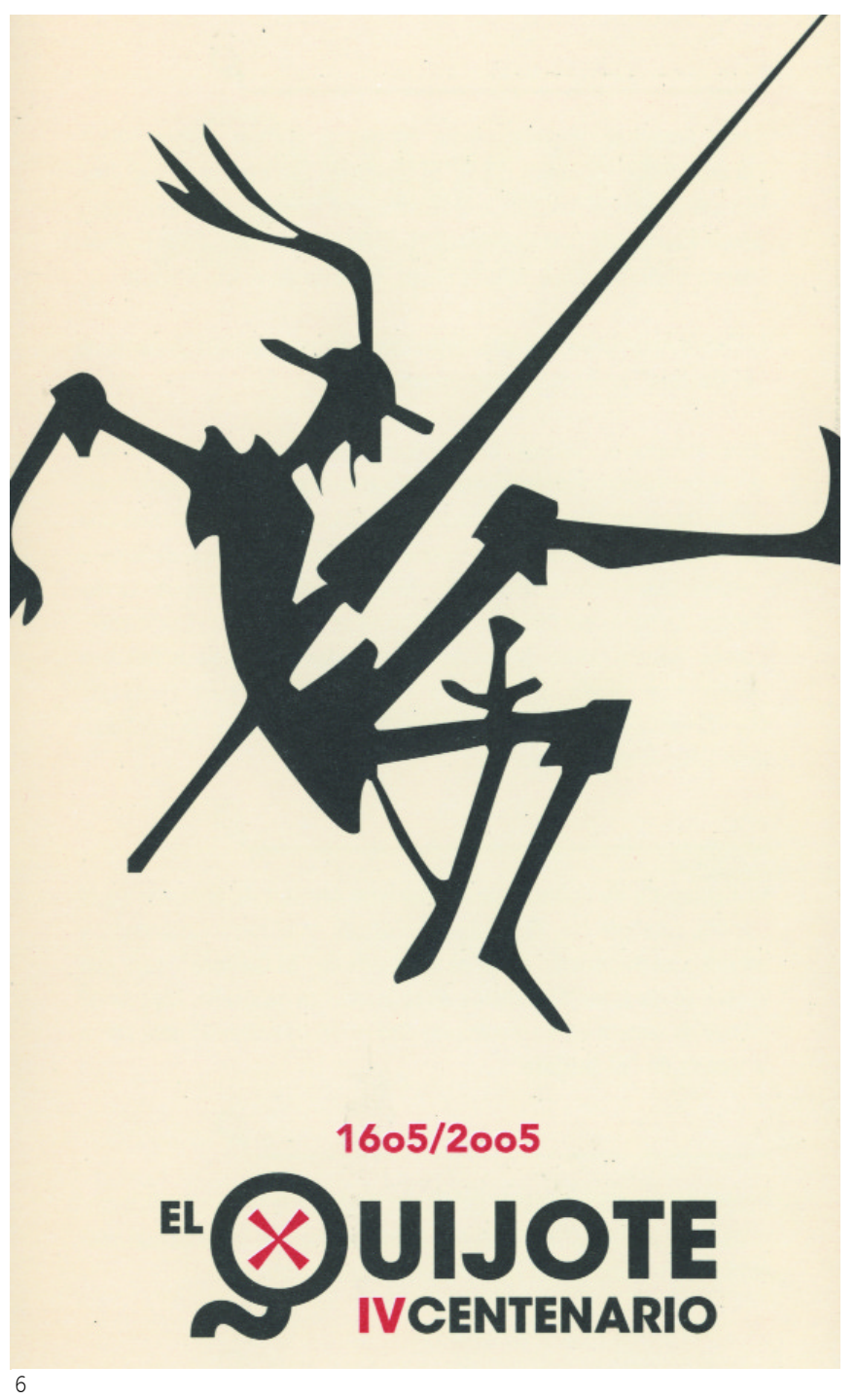

Madrid) o rojo (caso de Barcelona -casacas rojas- o Santiago -chaquetas rojas). En muchos casos realizan a la vez encuestas sobre gustos, tiempo de estancia, medio de transporte, utilizando estos datos para poder analizar la demanda turística de la ciudad. Otro tipo es el de informadores-guía que, como sucede en Zaragoza, están ubicados en diferentes edificios de la ciudad ofreciendo información turística de la ciudad y realizando visitas guiadas. En el caso de los autobuses turísticos, también los guías acompañantes ejercen su doble papel de guía e informador turístico.

En hostelería el desarrollo del turismo cultural en medio rural y urbano ha permitido la recuperación de edificios y conjuntos patrimoniales como hoteles o casas rurales. Estos establecimientos se agrupan en redes o cadenas que precisamente utilizan el patrimonio como elemento diferenciador, como es el caso de iniciativas públicas como Paradores, Pazos gallegos, las Posadas de Castilla y León, Casonas Asturianas, Palacios y Posadas en Cantabria, y privadas como Hosterías y Hospederías Reales (con su línea Hoteles Museo), Haciendas de España o Relais \& Chateaux.

Desde la restauración se ha apostado también por la calidad para posicionar la diversidad de nuestra gastronomía, participando de estas estrategias de tematización como se ha evidenciado en el Año Gaudi 2002, el Año Dalí 2004 o Año del Quijote 2005 con la recreación de la cocina de la época o la inspiración en la obra de los artistas en menús asociados a los eventos y servidos en restaurantes y hoteles.

En relación con el transporte turístico que han desarrollado productos de turismo cultural o con un componente cultural, como los transportes históricos, los trenes turísticos y los autobuses turísticos.

Otro punto en crecimiento y de creación de empleo son sin duda alguna las TIC que juegan un papel significativo en la valorización del patrimonio cultural y en su promoción turística. Russo (2004) afirma que la digitalización permite generar nuevos productos, nuevos mercados y modos de distribución, entre los que cabe destacar el acceso virtual y la experimentación a recursos culturales no visitables o inexistentes; acceso centralizado a recursos culturales y colecciones artísticas, con la posibilidad de descargar reproducciones digitales, objetos de arte o actuaciones; experimentar con material visual y sonoro (danza, lenguaje, vestuario, gastronomía...); creación de itinerarios temáticos de distintos recursos culturales y sitios monumentales según preferencias, presupuesto y tiempo disponible; ofrecer información y almacenamiento de material sobre un tema especifico (desde casa a través de la web o en el mismo lugar de destino con tecnología móvil), así como facilitar información y adquisición de provisiones turísticas complementarias (un restaurante cerca de un monumento, una visita guiada, etc.) basado en la información y evaluación de otros usuarios. 
6. Año del Quijote 2005. Folleto de actividades de la Consejeria de Cultura. Junta de Andalucía
Internet no es el único instrumento de aplicación de las TIC en relación con el turismo cultural, se está produciendo un importante desarrollo de aplicaciones de información personal mediante telefonía móvil y recursos individuales como los PDA (Personal Digital Assistant) o los DVD personalizados. El turismo cultural se ve reforzado por las aplicaciones multimedia que ofrecen servicios de preparación del viaje, especialmente ligados a la internet fija que permite acceder a portales de contenidos, realizar una visita virtual a un monumento histórico o museo, bien descargar contenidos y datos en un PDA o incluso en navegadores para vehículos que permiten disponer de la información necesaria en el transcurso del viaje. Según Bernardos (2003) existen otras posibilidades para acceder a la información mediante navegación WAP o i-Mode, aún no parece el medio más idóneo para acceder a gran cantidad de contenidos, tanto por el precio como por la velocidad y la disponibilidad restringida a determinadas áreas geográficas. En la actualidad están disponibles servicios de consulta de guía turística, transporte, hoteles, etc. a los que se puede acceder vía telefonía móvil. Con la banda ancha móvil se podrá ofertar la implantación de servicios más atractivos para los usuarios ya que soportará streaming de vídeo y audio a alta velocidad.

\section{Conclusiones}

El análisis realizado sobre el estado de la cuestión en nuestro pais permite mostrar que efectivamente, el turismo cultural se perfila como un importante yacimiento de empleo para los profesionales del patrimonio. Son varios los ámbitos de esta actividad económica que pueden generar empleo para dichos profesionales: gestores de monumentos, museos y centros de interpretación relacionados con el desarrollo turístico; guias e informadores turísticos, personal especializado para dotar de contenido y actualizar las posibilidades que ofrecen las TIC; personal docente cualificado; personal de entidades públicas o mixtas de promoción turística; consultoras; agencias de viaje y operadores especializados en el segmento de turismo cultural, etc.

Además, debemos tener en cuenta que en España, este tipo de turismo es aún un nicho de mercado no completamente explotado, con grandes posibilidades y en continuo crecimiento, frente a otras modalidades turísticas más tradicionales como es el caso del segmento de sol y playa. En este sentido, cabe señalar la necesidad de consensuar políticas eficaces entre los sectores cultural y turistico, asi como entre los sectores público y privado que permitan la creación y gestión de verdaderos productos turístico-culturales.

De todas formas, se hace evidente una necesidad por parte de las administraciones públicas de realizar estudios estadísticos sobre el empleo asociado a la vertiente cultural del turismo (tanto directo como indirecto), que incluyan los diferentes subsectores en los que se divide esta actividad. La reciente creación de observatorios turísticos en determinadas comunidades autónomas debería contemplar este aspecto. La obtención de estos datos permitiría evaluar y cuantificar el impacto del turismo cultural sobre la creación de puestos de trabajo, con el fin de diseñar y planificar las políticas de empleo dentro de este sector turístico.

\section{Notas}

${ }^{1}$ Este proyecto va dirigido a colectivos con desiguales oportunidades de acceso al empleo y con limitaciones en su posibilidad de desarrollo profesional en el mercado de trabajo: fundamentalmente, mujeres con titulaciones universitarias en especialidades humanisticas que sufren una situación de desempleo o bien ocupan empleos no relacionados con su cualificación. Para más información consultar www.femp.es/cultur_civitas/web/culturhr.htm

\section{Bibliografía}

ANTON, S. y VILLALTA, E. (2004) "La presencia en Internet de los principales destinos turísticos del litoral mediterráneo español", en V Congreso "Turismo y Tecnologías de la Información y las Comunicaciones" TuriTec 2004. Málaga, 3-15 octubre 2004. Universidad de Málaga, www.turismo.uma.es/turitec/turitec2004/ docs/actas_turitec_pdf/1.pdf

BERNARDOS A. (2003). Servicios móviles de localización. Aplicaciones en el sector turistico. CEDITEC. Universidad Politécnica Madrid. Madrid. http://www.ceditec.etsit.upm.es/Informes_globales/ceditec_loc.pdf

COMISIÓN EUROPEA (2003) Estructura, funcionamiento y competitividad del turismo europeo y de sus empresas. Oficina de Publicaciones Oficiales de las Comunidades Europeas. Luxemburgo

Díaz luQUe, P. GUEVARA, A. y CARO, J.L. (2004) "Promoción Turística de las Comunidades Autónomas en Internet", en V Congreso "Turismo y Tecnologías de la Información y las Comunicaciones" TuriTec 2004. Málaga, 3-15 octubre 2004. Universidad de Málaga, www.turismo.uma.es/turitec/turitec2004/docs/ actas_turitec_pdf/3.pdf

MARCHENA GÓMEZ, M.J. (ed.) Turismo urbano y patrimonio cultural. Patronato Provincial de Turismo de Sevilla, 1998

MATAMALA, J.C. y TRESSERRAS J. (2005) "Elementos básicos de comunicación e información a la demanda turística cultural" , en V Congreso Andaluz de Información Turística. Alhama de Granada, 14-16 marzo 2005. En prensa

RUSSO, A.P. (2004) "Portales culturales: e-Culture para un desarrollo sostenible en regiones turísticas", en Scripta Nova. Revista electrónica de Geografía y Ciencias Sociales. Universidad de Barcelona. Vol. VIII, núm. 170 (13), 1 agosto 2004, www.ub.es/geocrit/sn/sn-170-13.htm

TRESSERRAS, J. (2004) "La tematización de las ciudades: el uso de la cultura en las estrategias de desarrollo local y promoción del turismo urbano", en Turismo y Sociedad. Vol. VI. n 3. Facultad de Administración de Empresas Turísticas y Hoteleras de la Universidad Externado de Colombia. Bogotá, Colombia

TURESPAÑA (2001) Turismo cultural. Serie Estudios de Productos Turísticos, 